\title{
Are bovine teeth a suitable substitute for human teeth in in vitro studies to assess endotoxin load in root canals?
}

Tiago André Fontoura de MELO(a) Grasiela Sabrina Longhi GRÜNDLING(a)

Francisco MONTAGNER(b)

Roberta Kochenborger SCARPARO(a) José Antônio Poli de FIGUEIREDO(a) Fabiana Vieira VIER-PELISSER ${ }^{(a)}$

(a) Pontifícia Universidade Católica do Rio Grande do Sul - PUCRS, Dental School, Clinical Department, Porto Alegre, RS, Brazil.

(b) Universidade Federal do Rio Grande do Sul - UFRGS, Dental School, Endodontics Division, Porto Alegre, RS, Brazil.

Declaration of Interests: The authors certify that they have no commercial or associative interest that represents a conflict of interest in connection with the manuscript.

Corresponding Author:

Tiago André Fontoura de Melo

E-mail: tafmelo@gmail.com

DOI: 10.1590/1807-3107BOR-2015.vol29.0087

Submitted: Jan 19,2015

Accepted for publication: Mar 27, 2015

Last revision: Jun 03, 2015

\begin{abstract}
The present study aimed to determine the feasibility of using bovine teeth as a suitable alternative for human teeth, in experiments involving in vitro endotoxin contamination. Twenty bovine central incisors and 20 human single-root premolars had their dental crowns removed and root lengths set at $16 \mathrm{~mm}$. Root canals were prepared up to \#60 K-file size and sterilized with cobalt-60 gamma irradiation $(20 \mathrm{kGy}, 6 \mathrm{~h})$. The teeth were randomly divided into four groups: G1-bovine teeth (bovine negative control, $\mathrm{n}=10$ ), G2-human teeth (human negative control, $\mathrm{n}=10$ ), G3-bovine teeth, inoculated with Escherichia coli (055:B55) LPS, and G4-human teeth inoculated with E. coli LPS. The G1 and G2 groups were exposed to apyrogenic water. After the teeth had been incubated at $37^{\circ} \mathrm{C}$ and atmospheric humidity for $24 \mathrm{~h}$, the samples of solutions in the main canals were collected with apyrogenic absorbent paper tips. LPS levels were quantified using Limulus Amebocyte Lysate assay. The data obtained were statistically analyzed using one-way ANOVA, with a significance level of 5\%. A high amount of endotoxin was detected in the inoculated human teeth (G4) when compared to the sterilized teeth (G2), as well as in the inoculated bovine teeth (G3) when compared to the inoculated human teeth (G4). However, there was no statistical difference between bovine teeth before and after the $E$. coli endotoxin inoculation. Therefore, under the mentioned experimental conditions, the use of bovine teeth should not be a choice for laboratory research on endotoxin contamination.
\end{abstract}

Keywords: Dental Pulp Cavity; Endotoxins; Decontamination; Humans; Cattle.

\section{Introduction}

The use of human teeth in in vitro studies has decreased over time because of ethical issues, difficulty in obtaining samples of the correct size, and difficulty in standardizing the sample characteristics. ${ }^{1}$ Thus, animal teeth, such as teeth from pigs, ${ }^{2}$ rodents, ${ }^{3}$ and bovines,${ }^{4}$ have been increasingly employed in laboratorial studies and have consequently become a substitute for human teeth.

Bovine teeth can be easily acquired and handled due to their size. ${ }^{1}$ Moreover, the age and acquisition of intact bovine teeth can be controlled, which is an advantage. ${ }^{5}$ When compared, human and bovine teeth have 
few differences with regard to composition and tissue structure. Some studies report a similarity in their radiodensity, ${ }^{6}$ enamel thickness, and dentin surface hardness. ${ }^{7}$ However, the enamel prisms are higher and harder in bovine teeth. ${ }^{1}$ Both human and bovine teeth show similar dentinal tubule numbers and diameters in the crown. However, the average dentinal tubule diameter, particularly in the root, is larger in bovines than in humans. ${ }^{8}$ Moreover, the thickness of the peritubular dentin is greater in bovine teeth. ${ }^{9}$

Several studies have successfully used bovine central incisors as a substitute for human teeth, particularly tests investigating adherence and dental material micro-infiltration, ${ }_{10}^{10}$ resistance to fracture, shear bond strength, ${ }^{11}$ and microbiological tests. ${ }^{12}$

However, in vivo ${ }^{13}$ and in vitro ${ }^{14}$ experiments that assess the presence and levels of endotoxin in root canals have generally been carried out using human teeth So far, there is no other study that examines contamination by endotoxins in bovine teeth in order to validate this experimental model.

Thus, the present study aimed to verify the feasibility of using bovine teeth, sterilized with the cobalt-60 (20 kGy, $6 \mathrm{~h}$ ) protocol, as an alternative for human teeth in studies employing samples contaminated with bacterial lipopolysaccharide (LPS).

\section{Methodology}

The present study was approved by the Ethics Committee in Research of the Pontifícia Universidade Católica do Rio Grande do Sul - PUCRS (PUCRS, Protocols numbers 5859 and 811207).

\section{Sample selection and preparation}

Twenty bovine central incisors and 20 human single-root premolars were selected. They were sectioned transversally to stardardize the root length at $16 \mathrm{~mm}$. The working length was set at $15 \mathrm{~mm}$. All the canals were prepared manually using the serial technique up to \#60 hand K-files (Dentsply/Maillefer Instruments S.A., Ballaigues, Switzerland), and irrigated with $2 \%$ sodium hypochlorite solution (Iodontosul, Porto Alegre, Rio Grande do Sul, Brazil).

The smear layer of the root canal was obtained using 17\% EDTA (Iodontosul, Porto Alegre, Brazil) for $5 \mathrm{~min}$, and then shaking with file \#60 for one minutes.
The final irrigation was performed using $2 \mathrm{~mL}$ of $2 \%$ sodium hypochlorite solution. The root canals were dried with sterilized paper points (Dentsply/Maillefer Instruments S.A., Ballaigues, Switzerland).

Samples were divided into four groups according to species (human and bovine) and presence or absence of LPS contamination (negative and positive): G1-bovine teeth (bovine negative control, $\mathrm{n}=10$ ); G2-human teeth (human negative control, $\mathrm{n}=10$ ); G3-bovine teeth, inoculated with Escherichia coli (055:B55) LPS; and G4-human teeth, inoculated with E. coli LPS. All teeth were stabilized on cell-culture plates (12 wells, $\mathrm{TPP}^{\circledR}$, Trasadingen, Switzerland), using Durepoxi ${ }^{\circledR}$ (Henkel, Düsseldorf, Germany).

The plates with the teeth and material used in this study were apyrogenized by cobalt- 60 gamma irradiation (20 kGy, for $6 \mathrm{~h}$ ) (Empresa Brasileira de Radiações - EMBRARAD, Cotia, Brazil), as previously described. ${ }^{15}$

\section{Specimen contamination}

The sample contamination protocol was in accordance with Signoretti et al. ${ }^{16}$ The positive bovine and positive human teeth groups were inoculated inside a laminar air flow cabinet, with $30 \mu \mathrm{L}$ of a solution containing E.coli O55:B5 endotoxin, (Lonza, Walkersville, USA) using a micropipette.

The LPS solution $(80 \mathrm{EU} / \mathrm{mL})$ was previously diluted in apyrogenic water to approximately $50.37 \mathrm{EU} / \mathrm{mL}$, for standardization of contamination and use.

In G1 and G2 (groups without LPS inoculation), the root canal was filled with $30 \mu \mathrm{L}$ of apyrogenic water.

Apyrogenic cotton pellets were placed in the cervical portion of the root canals and the plates with the samples were sealed and incubated for $24 \mathrm{~h}$ at $37^{\circ} \mathrm{C}$, and humidity.

\section{Determination of LPS levels}

All root canals were filled with $10 \mu \mathrm{L}$ of apyrogenic water before collection of samples. The fluid from the main root canal was collected with three \#60 absorbent, apyrogenic paper points (Tanari ${ }^{\circledR}$, Manaus, Brazil) that were held in position for 10 seconds. They were then transferred into apyrogenic glass tubes, sealed, and kept at $-20^{\circ} \mathrm{C}$ until the quantification of LPS levels could be carried out. The LPS content was 
also assessed in the apyrogenic water samples and in the paper tips employed during the experiment.

The glass tubes containing the paper tips were filled with $1 \mathrm{~mL}$ of apyrogenic water, heated to $37^{\circ} \mathrm{C}$ for one $h$, and vortexed (1 min, 3.000 RPM, Vortex AP56, Phoenix, Araraquara, Brazil).

The chromogenic-kinetic test of turbidimetric Limulus Amoebocyte Lysate (LAL) assay (Pyrogent $5000^{\circledR}$, BioWhitaker, Cambrex Co., Walkersville, USA) was used to quantify LPS levels in the root canals, as described by Xavier et al. ${ }^{17}$

The samples collected from the canals were mixed with LAL reagent and automatically monitored by a microplate reader/WinKQCL ${ }^{\mathrm{TM}}$ Software. Using the initial absorbance reading of each well as its own blank, the reader determines the time required for the absorbance to increase 0.03 absorbance units. This is termed as reaction time. The WinKQCL ${ }^{\mathrm{TM}}$ Software automatically performs a $\log / \log$ linear correlation of the Reaction Time of each standard and its corresponding endotoxin concentration. Increase in optical density is measured by the reaction time, which is inversely proportional to the quantity of LPS present in the sample.

A standard curve was drawn using known concentrations of the endotoxin, supplied by the kit, for use as a parameter for the quantification of LPS levels. All the samples collected for the purpose of analysis and quantification were diluted 10 times.

The assays were duplicated in different wells, in a 96 well micro-plate (Corning Costar, Cambridge, USA). For the negative control, $100 \mu \mathrm{L}$ of apyrogenic water were added, $100 \mu \mathrm{L}$ standard endotoxin at different concentrations for the curve, and $100 \mu \mathrm{L}$ of each sample for quantification. LPS levels were measured according to the manufacturer's instructions.

The microplate was incubated at $37 \pm 1^{\circ} \mathrm{C}$ for $10 \mathrm{~min}$ in the enzyme immunoassay reader (Ultramark, Bio-Rad Laboratories Inc., Hercules, USA) that was coupled with a computer that had the Wink QCL version 4 (BioWittaker, Cambrex CO., Walkersville, USA) software installed.

After the incubation period, $100 \mu \mathrm{L}$ of $\mathrm{LAL}$ chromogenic-kinetic reagent (Sigma Chemical Company, Saintt Louis, USA) was added to each well, thus commencing the reading and quantification of LPS levels.

\section{Statistical analysis}

$\mathrm{EU} / \mathrm{mL}$ measures were logarithmically transformed in order to reduce asymmetry and heteroscedasticity. The data were described using geometric mean, maximum, and minimum values. The groups were compared by carrying out one-way variance analysis (ANOVA one-way) on the logarithms. Significance level was 5\% ( $p \leq 0.05)$. Statistical analysis was performed using SPSS 13.0 software (SPSS Inc., Chicago, USA).

\section{Results}

In order to validate the turbidimetric LAL assay, the standard curve followed the linearity criteria $(r=1)$.

Endotoxin contamination levels $(<0.0100 \mathrm{EU} / \mathrm{mL})$ were not detected in the material used (apyrogenic water and absorbent paper tips) during the collection process.

The results of the analysis of the experimental groups are shown in Figure. A large amount of endotoxin was detected in inoculated human teeth (G4) when compared to the sterilized teeth (G2) and in inoculated bovine teeth (G3) when compared to inoculated human teeth (G4) $(\mathrm{p}<0.01)$. However, no statistical difference was detected in the bovine teeth before and after $E$. coli endotoxin inoculation ( $p>0.05)$.

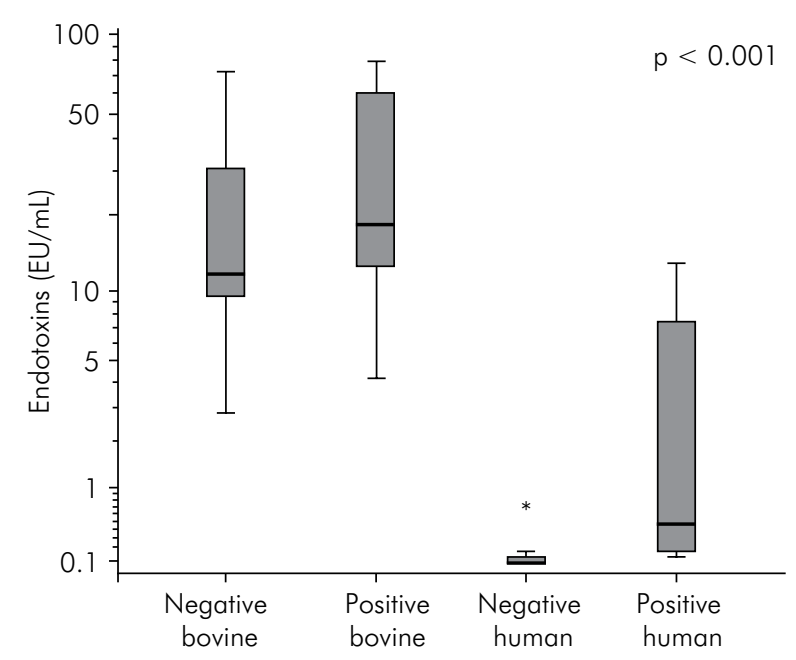

Figure. Each experimental group boxplot distribution of the endotoxin concentration in $\mathrm{EU} / \mathrm{mL}$. 


\section{Discussion}

Studies on the actions of irrigants, intracanal medicaments, and new technologies have been frequently performed as it is possible to inactivate and eliminate bacterial LPS from inside the root canal system.

LPS is an immunological mediator that is released during bacterial multiplication and death. It plays an important role in apical periodontitis pathogenesis. Besides its harmful biological effects, LPS can penetrate the dentin tubules four times deeper than the bacterium itself. ${ }^{18}$ In endodontics, the most reliable experimental model for assessment of LPS behavior inside the root canal system, involves extracted teeth. The most widely used experimental model employs human teeth, ${ }^{13,14}$ which has its limitations. Studies investigating endotoxins in animal models (e.g., dogs) have been carried out, ${ }^{19}$ even though approval and authorization for the use endotoxins have been restricted. Therefore, extracted bovine teeth may be a suitable substitute for human teeth; however, it is necessary to know whether the experimental model of bovine teeth is a feasible option for studies on endotoxin quantification.

The use of human or bovine extracted roots for in vitro studies, instead of in vivo models, has some advantages such as achievement of sample apyrogenization, followed by introduction of a standardized amount of endotoxin into the sample. The cobalt- 60 gamma irradiation protocol has been employed in several studies ${ }^{13,14}$ to produce tooth samples without endotoxins The materials and teeth used in this study were sterilized using the same protocol [cobalt-60 irradiation (20 kGy for 6 h)], in order to eliminate pre-existing endotoxins. ${ }^{20}$ The sterilization and decontamination process, using ionized energy, consists of exposing the products to electromagnetic short waves generated from the sealed sources of cobalt-60. When those waves meet the live organisms present in the sample being treated, they cause DNA rupture which leads to failure or incapacity to reproduce. Due to the high penetration power of the electromagnetic waves, live organisms can be reached wherever they are irrespective of the manner of packaging used. However, the protocol used in this study was not effective for bovine teeth. It was observed that the samples from G1 (sterilized bovine teeth) had the same level of endotoxins as the teeth from G3 (sterilized bovine teeth exposed to endotoxin contamination). There was a tendency for increased LPS load in the positive group (G3), possibly due to death of the bacteria already present in the canal, or the identification of endotoxins that were already present in the sample. It might be necessary to test different disinfection protocols with different irradiation doses $(\mathrm{kGy})$, in order to make the bovine dental pieces apyrogenic different irradiation doses (kGy), in order to achieve sterilization of bovine dental pieces. However, according to Soares et al., ${ }^{21}$ high irradiation power increased the chances of damage to the dentin structure. This damage may be in the form of cracks, particularly in the peritubular dentin, and can compromise the use of that sample in certain kinds of experiments.

The results obtained from human teeth (negative and positive groups) are in accordance with the results previously reported by Maekawa et al..$^{22}$ and Signoretti et al., ${ }^{16}$ who employed the same detoxification protocol for human teeth.

Considering the possibility of pre-existent contamination in bovine teeth, some studies have observed an association between E.coli O157:H7 and its endotoxins and cattle and bovine by-products, leading researchers to look for ways to solve this zoonosis by means of specific slaughtering practices and carcass decontamination protocols. ${ }^{23,24}$ Many factors, such as age, ${ }^{25,26}$ season of the year, ${ }^{27}$ diet ${ }^{28}$ animal stress when slaughtered, ${ }^{29}$ and confined environments, can affect contamination $^{30}$ The bovine dental carcass used in this study may have already been contaminated with endotoxins during transportation or storage. However, even if the dental sample had been contaminated during handling, the results obtained in the negative control group cannot be justified as the pieces had been apyrogenized before being used. Furthermore, some microbial species from bovine teeth may not have been eliminated by the irradiation dose applied in the study. Therefore, the sterilization process employed in the present study (cobalt- 60 irradiation, $20 \mathrm{kGy}$, for $6 \mathrm{~h}$ ) did not have the same efficacy as that observed with human teeth. 


\section{Conclusions}

According to the results obtained in the present study, the use of bovine teeth sterilized with cobalt-60 20 kGy irradiation for $6 \mathrm{~h}$ was not a suitable alternative for human teeth in in vitro research on E.coli LPS. Further studies should be carried out to determine an ideal protocol

\section{References}

1. Almeida KG, Scheibe KG, Oliveira AE, Alves CM, Costa JF. Influence of human and bovine substrate on the microleakage of two adhesive systems. J Appl Oral Sci. 2009 Mar-Apr;17(2):92-6.

2. Sousa CJ, Pereira MC, Almeida RJ, Loyola AM, Silva AC, Dantas NO. Synthesis and characterization of zinc oxide nanocrystals and histologic evaluation of their biocompatibility by means of intraosseous implants. Int Endod J. 2014 May;47(5):416-24.

3. Khalil WA, Eid NF. Biocompatibility of BioAggregate and mineral trioxide aggregate on the liver and kidney. Int Endod J. 2013 Aug;46(8):730-7.

4. Brito-Júnior M, Pereira RD, Veríssimo C, Soares CJ, Faria-e-Silva AL, Camilo CC, Sousa-Neto MD. Fracture resistance and stress distribution of simulated immature teeth after apexification with mineral trioxide aggregate. Int Endod J. 2014 Oct;47(10):958-66.

5. Wilder AD Jr, Swift EJ Jr, May KN Jr, Waddell SL. Bond strengths of conventional and simplified bonding systems. Am J Dent. 1998 Jun;11(3):114-7.

6. Fonseca RB, Haiter-Neto F, Carlo HL, Soares CJ, Sinhoreti MA, Puppin-Rontani RM, et al. Radiodensity and hardness of enamel and dentin of human and bovine teeth, varying bovine teeth age. Arch Oral Biol. 2008 Nov;53(11):1023-9.

7. Donassollo TA, Romano AR, Demarco FF, Della-Bona I. Avaliação da microdureza superficial do esmalte e da dentina de dentes bovinos e humanos (permanentes e decíduos). Rev Odonto Cienc. 2007;22(58):311-6.

8. Camargo CH, Siviero M, Camargo SE, Oliveira SH, Carvalho CA, Valera MC. Topographical, diametral, and quantitative analysis of dentin tubules in the root canals of human and bovine teeth. J Endod. 2007 Apr;33(4):422-6.

9. Dutra-Correa M, Anauate-Netto C, Arana-Chavez VE. Density and diameter of dentinal tubules in etched and non-etched bovine dentine examined by scanning electron microscopy. Arch Oral Biol. 2007 Sep;52(9):850-5.

10. Firoozmand LM, Brandão JV, Fialho MP. Influence of microhybrid resin and etching times on bleached enamel for the bonding of ceramic brackets. Braz Oral Res. 2013 Mar-Apr;27(2):142-8. for preparation and apyrogenization of bovine dental specimens.

\section{Acknowledgments}

This study was supported by grants from Fundação de Amparo à Pesquisa do Estado do Rio Grande do Sul (FAPERGS-Protocol 12/0439-0).

11. Costa LA, Carneiro KK, Tanaka A, Lima DM, Bauer J. Evaluation of $\mathrm{pH}$, ultimate tensile strength, and micro-shear bond strength of two self-adhesive resin cements. Braz Oral Res. 2014 Jan-Feb;28(1):1-7.

12. Rossi-FedeleG, Roberts AP. A preliminary study investigating the survival of tetracycline resistant Enterococcus faecalis after root canal irrigation with high concentrations of tetracycline. Int Endod J. 2007 Oct;40(10):772-7.

13. Sousa EL, Martinho FC, Nascimento GG, Leite FR, Gomes BP. Quantification of endotoxins in infected root canals and acute apical abscess exudates: monitoring the effectiveness of root canal procedures in the reduction of endotoxins. J Endod. 2014 Feb;40(2):177-81.

14. Marinho AC, Martinho FC, Zaia AA, Ferraz CC, Gomes BP. Influence of the apical enlargement size on the endotoxin level reduction of dental root canals. J Appl Oral Sci. 2012 Nov-Dec;20(6):661-6.

15. Oliveira LD, Carvalho CA, Carvalho AS, Alves JS, Valera MC, Jorge AO. Efficacy of endodontic treatment for endotoxin reduction in primarily infected root canals and evaluation of cytotoxic effects. J Endod. 2012 Aug;38(8):1053-7.

16. Signoretti FG, Gomes BP, Montagner F, Tosello FB, Jacinto RC. Influence of $2 \%$ chlorhexidine gel on calcium hydroxide ionic dissociation and its ability of reducing endotoxin. Oral Surg Oral Med Oral Pathol Oral Radiol Endod. 2011 May;111(5):653-8.

17. Xavier AC, Martinho FC, Chung A, Oliveira LD, Jorge $\mathrm{AO}$, Valera $\mathrm{MC}$, et al. One-visit versus two-visit root canal treatment: effectiveness in the removal of endotoxins and cultivable bacteria. J Endod. 2013 Aug;39(8):959-64.

18. Gomes BP, Martinho FC, Vianna ME. Comparison of $2.5 \%$ sodium hypochlorite and $2 \%$ chlorhexidine gel on oral bacterial lipopolysaccharide reduction from primarily infected root canals. J Endod. 2009 Oct;35(10):1350-3.

19. Tanomaru JM, Leonardo MR, Tanomaru Filho M, Bonetti Filho I, Silva LA. Effect of different irrigation solutions and calcium hydroxide on bacterial LPS. Int Endod J. 2003 Nov;36(11):733-9.

20. Tsuji K, Harrison SJ. Limulus amebocyte lysate - a means to monitor inactivation of lipopolysaccharide. Prog Clin Biol Res. 1979;29:367-78. 
- Are bovine teeth a suitable substitute for human teeth in in vitro studies to assess endotoxin load in root canals?

21. Soares CJ, Castro CG, Neiva NA, Soares PV, Santos-Filho PC, Naves LZ, et al. Effect of gamma irradiation on ultimate tensile strength of enamel and dentin. J Dent Res. 2010 Feb;89(2):159-64.

22. Maekawa LE, Valera MC, Oliveira LD, Carvalho CA, Koga-Ito $\mathrm{CY}$, Jorge AO. In vitro evaluation of the action of irrigating solutions associated with intracanal medications on Escherichia coli and its endotoxin in root canals. J Appl Oral Sci. 2011 Apr;19(2):106-12.

23. Castillo A, Lucia LM, Goodson KJ, Savell JW, Acuff GR. Decontamination of beef carcass surface tissue by steam vacuuming alone and combined with hot water and lactic acid sprays. J Food Prot. 1999 Feb;62(2):146-51.

24. Berry ED, Cutter CN. Effects of acid adaptation of Escherichia coli O157:H7 on efficacy of acetic acid spray washes to decontaminate beef carcass tissue. Appl Environ Microbiol. 2000 Apr;66(4):1493-8.

25. Cray WC Jr, Moon HW. Experimental infection of calves and adult cattle with Escherichia coli O157:H7. Appl Environ Microbiol. 1995 Apr;61(4):1586-90.
26. Nielsen EM, Tegtmeier C, Andersen HJ, Grønbaek C, Andersen JS. Influence of age, sex and herd characteristics on the occurrence of Verocytotoxin-producing Escherichia coli O157 in Danish dairy farms. Vet Microbiol. 2002 Sep 2;88(3):245-57.

27. Hancock DD, Besser TE, Rice DH, Herriott DE, Tarr PI. A longitudinal study of Escherichia coli O157 in fourteen cattle herds. Epidemiol Infect. 1997 Apr;118(2):193-5.

28. Diez-Gonzalez F, Callaway TR, Kizoulis MG, Russell JB. Grain feeding and the dissemination of acid-resistant Escherichia coli from cattle. Science. 1998 Sep 11;281(5383):1666-8.

29. Cray WC Jr, Casey TA, Bosworth BT, Rasmussen MA. Effect of dietary stress on fecal shedding of Escherichia coli O157:H7 in calves. Appl Environ Microbiol. 1998 May;64(5):1975-9.

30. Shere JA, Bartlett KJ, Kaspar CW. Longitudinal study of Escherichia coli O157:H7 dissemination on four dairy farms in Wisconsin. Appl Environ Microbiol. 1998 Apr;64(4):1390-9. 